\title{
CASO OURO FINO SAÚDE ANIMAL
}

\author{
Bernardo Hauch Ribeiro de Castro \\ bercastro@gmail.com
}

Universidade Federal do Rio de Janeiro - Rio de Janeiro, RJ / Brasil

\begin{abstract}
Recebido em 02/03/2010
Aprovado em 22/03/2011

Disponibilizado em 01/04/2012

Avaliado pelo sistema double blind review

Revista Eletrônica de Administração

Editor: Luís Felipe Nascimento

ISSN 1413-2311 (versão on-line)

Editada pela Escola de Administração da Universidade Federal do Rio Grande do Sul.

Periodicidade: Quadrimestral
\end{abstract}

Sistema requerido: Adobe Acrobat Reader.

\section{RESUMO}

O Caso Ouro Fino Saúde Animal ilustra uma tomada de decisão, pelos executivos da empresa, sobre a entrada em um novo mercado, de vacinas para bovinos. Diante da necessidade de dar um passo maior em direção ao crescimento sustentável, a empresa não poderia deixar de entrar nesse segmento, que representava mais de metade do mercado brasileiro de produtos veterinários. No entanto, era um passo arriscado. A principal questão do caso é avaliar as alternativas de comprar vacinas de terceiros ou produzir internamente suas próprias vacinas. A empresa do caso é a Ouro Fino Saúde Animal, empresa brasileira de produtos veterinários, instalada no Estado de São Paulo, com faturamento de mais de R \$ 100 milhões anuais. Os dois principais personagens deste caso são os diretores financeiro e industrial da empresa. A situação passa-se em 2005. Como instrumento de ensino, o caso foi concebido para o ensino de estratégia em cursos de pós-graduação em administração, levando os alunos a avaliar vantagens e desvantagens de cada uma das alternativas. Como objetivo secundário, o caso propicia alguns elementos para uma estimativa da viabilidade financeira da opção de implantar uma nova unidade produtiva e a possibilidade de refletir sobre uma decisão já tomada, de entrada no novo mercado. Por fim, o caso traz uma série de informações sobre o mercado brasileiro e sobre o mercado mundial de produtos veterinários. É possível, com base nestes dados, trabalhar questões ligadas à segmentação e posicionamento da empresa no setor, ficando a critério do professor este tipo de uso.

Palavras-chave: indústria veterinária, caso de ensino, estratégia, vacina, saúde animal.

\section{OURO FINO SAÚDE ANIMAL CASE}

\begin{abstract}
The present teaching case illustrates a decision-making by company executives, on entry into a new market of vaccines for cattle. Faced with the need to take a major step toward sustainable growth, Ouro Fino Saúde Animal could not fail, as long as it represented more
\end{abstract}


than half the market of veterinary products. However, it was a risky step. The main issue of the case is to evaluate wether to buy third-part vaccines or to produce internally their own vaccines. The case company is Ouro Fino Saúde Animal, a Brazilian industry of veterinary products, located in the State of São Paulo, with sales over R\$ 100 million annually. The two main characters of this case are the financial and industrial directors. The situation is set in 2005. As a teaching tool, the case was designed for teaching Strategy in post-graduate in management, leading students to assess the advantages and disadvantages of each alternative. As a secondary objective, the case provides some elements for an estimate of the viability of the option to start a new production unit and the possibility of reflecting on a decision already made, to enter the new market. Finally, the case has a lot of information about the Brazilian and the global market for veterinary products. It is possible, based on these data, work on segmentation and positioning topics, left to the discretion of the teacher such use.

Keywords: veterinary products industry, teaching case, strategy, vaccine, animal health.

\section{CASO OURO FINO SAÚDE ANIMAL}

\section{RESUMEN}

El Caso Ouro Fino Saúde Animal ilustra una toma de decisiones por los ejecutivos de la empresa, a la entrada en un nuevo mercado de las vacunas para el ganado. Ante la necesidad de dar un paso importante hacia el crecimiento sostenible, Ouro Fino Saúde Animal no podía dejar de entrar, ya que representaba más de la mitad del mercado de productos veterinarios. Sin embargo, fue un paso arriesgado. El principal problema del caso es evaluar las alternativas de la compra de vacunas o de producir internamente sus propias vacunas. La compañía es la Ouro Fino Saúde Animal, una industria brasileña de productos veterinarios, ubicada en el Estado de Sao Paulo, con ventas de más de R \$ 100 millones anuales. Los dos personajes principales de este caso son los directores financieros e industriales de la empresa. La situación se describe en el 2005. Como herramienta de enseñanza, el caso fue diseñado para la estrategia de enseñanza en el post-grado en la gestión, los estudiantes que conducen a evaluar las ventajas y desventajas de cada alternativa. Como objetivo secundario, el caso proporciona algunos elementos para una estimación de la viabilidad financiera de la opción de desplegar una nueva unidad de producción y la posibilidad de reflexionar sobre una decisión ya tomada, para entrar en el mercado. Por último, el caso tiene una gran cantidad de información sobre el mercado y en el mercado mundial de productos veterinarios. Es posible, sobre la base de estos datos, a la discreción del profesor, trabajar las cuestiones de segmentación y posicionamiento de la compañía en la industria.

Palabras clave: industria veterinaria, caso de enseñanza, estrategia, vacuna, sanidad animal.

\section{INTRODUÇÃO}

Numa das salas de sua nova sede no interior de São Paulo, os sócios aguardavam ansiosamente pela reunião com seus dois principais executivos. Eles trariam as ideias para o futuro do Grupo Ouro Fino. 
Com o rápido crescimento, algumas questões vinham à tona. Como manter o crescimento sustentável? Como criar as condições para tal? Como traçar a rota para se tornar uma grande empresa de produtos veterinários?

Os sócios esperavam as respostas para estas perguntas. O diretor financeiro e o diretor industrial sabiam que o que tinha sido alvo de longas conversas ao longo do tempo que trabalharam juntos teria que ser sintetizada neste momento. A mudança de patamar só viria com a entrada em um novo mercado, por sinal o maior mercado no Brasil, o de comercialização de vacinas para febre aftosa. A dúvida era como entrar neste mercado.

A produção das vacinas internamente seria muito cara, pois dependia de novas instalações, a empresa nunca tinha produzido vacinas, o mercado era muito regulado e o risco de não se chegar a resultados razoáveis estava sempre presente. Por outro lado, daria bastante flexibilidade e autonomia para a empresa. Já a compra da vacina no mercado parecia ser uma alternativa válida, dado que havia uma razoável padronização, várias empresas a produziam e a entrada da Ouro Fino no mercado seria muito mais rápida. Enfim, o que fazer?

\section{O Começo}

$\mathrm{Na}$ década de 80, um técnico agrícola trabalhava como representante comercial em uma empresa de ração para gado. Ele visitava as fazendas e apresentava linhas de produtos no interior de São Paulo. Nessa atividade, acabava tendo contato direto com produtores, donos de lojas e cooperativas. Conhecendo o mercado consumidor de perto, identificou algumas necessidades não atendidas. "Ficamos dois anos revendendo produtos, até que percebemos que seria possível fabricar alguns deles. Estudei a legislação, me habilitei junto ao Ministério da Agricultura e obtive o primeiro registro de produto". Juntou-se a um amigo de infância e criou a Produtos Veterinários Ouro Fino na década de 80, em uma cidade do interior de São Paulo. No início eram 3 funcionários, os dois sócios nas vendas e a esposa de um deles na parte administrativa. "O negócio deu tão certo que um ano após os inícios das atividades nós já possuíamos oito produtos registrados e comercializando nossa produção própria".

As linhas de produtos, que no início estavam focadas no ramo avícola, cresceram rapidamente e já envolviam itens para diversas espécies em várias formas: soluções, suspensões, pomadas e sólidos, podendo ser de aplicação via oral, injetável ou dermal. Havia produtos para bovinos, equinos, ovinos, aves e suínos.

Já em 1996, a empresa começou sua inserção no mercado internacional, com as primeiras exportações. A forte demanda levou a empresa a estabelecer, em 1997, uma subsidiária no México. Em 2004, já exportava para quase todos os países da América do Sul e 
para 15 países africanos. As exportações, que somavam R 274 mil em 1997, ou 1,3\% do faturamento, subiram para mais de R\$ 14 milhões em 2005, ou 12,4\% do faturamento.

\section{O Crescimento}

A empresa teve um crescimento rápido e financiado, no início, em grande parte por capital próprio. No período de 1997 a 2004, a empresa cresceu, em média, 21\% ao ano. O quadro de pessoal cresceu também na mesma ordem, a uma taxa de $16 \%$ ao ano.

Quanto à sua participação no mercado, a empresa apresentou um crescimento constante, elevando sua participação de 2,4\% em 1997 para 2,8\% em 2001 e beirando os 3,8\% em 2004. Isso foi acompanhado de uma escalada no ranqueamento das empresas fabricantes de produtos veterinários no Brasil, atingindo o $9^{\circ}$ lugar em 2004 (Anexo 1).

Ao longo dos anos, a empresa passou a se focar cada vez mais no segmento de bovinos, que representou a maior parte dos negócios da empresa em 2004 (51\%). O segmento de Aves e Suínos representava 15\%, a Exportação 12\% e a Linha Pet 10\%.

\section{Segmentação}

Em relação à segmentação de mercado pelas classes terapêuticas, o SINDAN Sindicato Nacional da Indústria de Produtos para Saúde Animal o classifica em 10 grupos:

Tabela 1 - Segmentação de mercado por classes terapêuticas

\begin{tabular}{ll}
\hline Biológicos & \multicolumn{1}{c}{ Segmentação de mercado por classes terapêuticas } \\
\hline Antimicrobianos & $\begin{array}{l}\text { Denominação de produtos terapêuticos obtidos com base em organismos vivos ou } \\
\text { derivados destes, como soros, vacinas, antitoxinas e antígenos. }\end{array}$ \\
\hline Ectoparasiticidas & $\begin{array}{l}\text { Substâncias que inibem o crescimento de microrganismos ou os destroem. Quando esses } \\
\text { agentes são originalmente produzidos por espécies de microrganismos, são denominados } \\
\text { antibióticos. Quando são produzidos de forma sintética, denominam-se quimioterápicos. }\end{array}$ \\
\hline Endectocidas & $\begin{array}{l}\text { Substâncias utilizadas para o tratamento de ectoparasitoses (parasitas externos) causadas } \\
\text { por moscas, ácaros, pulgas e carrapatos. }\end{array}$ \\
\hline Endoparasiticidas & $\begin{array}{l}\text { Substâncias que combatem os principais ectoparasitos e endoparasitos que atacam os } \\
\text { animais. Com o aparecimento de focos de resistência, os endectocidas são a primeira } \\
\text { opção no controle das ecto/endoparasitoses. }\end{array}$ \\
\hline Terapêuticos & $\begin{array}{l}\text { Substâncias farmacêuticas utilizadas no controle de parasitas internos, tais como vermes. } \\
\text { Substâncias químicas utilizadas para a prevenção e o tratamento de doenças, tratamentos } \\
\text { endócrinos, sintomas inflamatórios, entre outros. Nesse grupo estão incluídos } \\
\text { antiinflamatórios, analgésicos e hormônios (natural e sintético). }\end{array}$ \\
\hline Tônicos/Fortificantes & Produtos utilizados para restabelecer e reestruturar o estado geral do animal. \\
\hline Desinfetantes & $\begin{array}{l}\text { Para higienização de instalações e equipamentos de criação de animais em geral. Nessa } \\
\text { classe incluem-se também os anti-sépticos para a desinfecção de ferimentos nos animais. }\end{array}$ \\
\hline Dermatológicos & Substâncias indicadas para prevenção e tratamento de doenças de pele. \\
\hline Outros & Agrupa vários tipos de produtos, como suplementos nutricionais e embelezadores. \\
\hline
\end{tabular}


De todos os grupos indicados, a Ouro Fino só não participava dos Biológicos. Em todos os outros grupos, mantinha, em 2001, uma participação que variava de 1,3\% nos desinfetantes até 8,0\% no grupo de dermatológicos. No caso dos antimicrobianos, um dos maiores segmentos, a participação da empresa era de 3,3\%. Em 2004, a empresa comercializava mais de 120 produtos para mais de 8 mil clientes no Brasil.

$\mathrm{O}$ fato de não possuir qualquer produto no segmento de Biológicos trazia entraves ao crescimento da empresa. Em épocas de campanha de vacinação contra a febre aftosa, as vendas dos produtos da empresa acabavam caindo, pois havia uma tendência de que os produtores rurais comprassem "pacotes" que incluíam a vacina e outros produtos. Além disso, o segmento de biológicos respondia por $29 \%$ do mercado brasileiro e $23 \%$ do mercado mundial (Anexo 2). Entrar neste segmento era visto como crucial.

\section{A Nova Fábrica}

O crescimento acelerado começou a causar problemas de espaço. A empresa, inicialmente instalada em um pequeno imóvel de uma cidade do interior de São Paulo, enfrentou uma breve crise. A empresa se expandiu ocupando os imóveis vizinhos. Depois de alguns anos, a empresa já possuía um quarteirão e boa parte do quarteirão vizinho. As construções, que já existiam, eram adaptadas para permitir o trânsito de equipamentos. As empilhadeiras frequentemente transitavam na rua que separava os dois quarteirões da empresa. A empresa já enfrentava a reclamação de moradores do bairro, que viam o crescimento da empresa como uma ameaça.

A empresa então decidiu montar uma nova fábrica. "As lanchonetes do bairro ficaram desapontadas com a gente. Afinal, boa parte do movimento era de pessoal daqui”.

A ideia inicial era ocupar uma das vagas abertas no Condomínio Industrial da cidade. Logo viram que uma instalação neste tipo de arranjo talvez prejudicasse uma expansão futura.

Sob convite do prefeito de um município vizinho, a empresa decidiu se instalar em um grande terreno às margens da rodovia.

A nova fábrica tinha sido idealizada para ser uma das mais modernas instaladas no Brasil. O investimento total fora de US\$ 15 milhões e multiplicou a capacidade instalada em relação à antiga fábrica. Algumas dívidas foram contraídas para este investimento.

A empresa, que antes utilizava capacidade de terceiros para a fabricação de comprimidos, penicilínios e suplementos, inverteu os papéis. Passou a prestar serviços para outros fabricantes de produtos veterinários no Brasil, utilizando parte de sua capacidade. 
A nova fábrica, inaugurada em 2004, foi projetada durante dois anos para atender totalmente aos requisitos internacionais. Toda monitorada por um sistema computadorizado, a fábrica possuía um piso técnico isolado, acima da área de produção, onde ficava todo o maquinário de suporte, como os sistemas de aquecimento, resfriamento e ventilação. Todo esse custo tinha um objetivo: entrar nos mercados mais exigentes. Estados Unidos, Europa e Austrália eram os próximos destinos dos produtos da empresa.

\section{Formação do Grupo}

Em 2003, o Grupo, antes apenas dividido em mercado interno e externo, foi reestruturado em cinco unidades de negócio, com uma segmentação por mercado atendido. Uma delas atendia o segmento de bovinos, equinos, ovinos, caprinos, aves e suínos, respondendo pela maior parte das vendas. As demais eram dedicadas à linha de animais de companhia, à linha de sementes para pasto, à linha de cuidados domésticos (inseticidas, raticidas e produtos para jardinagem) e a última era responsável pelo mercado externo.

\section{O Mercado de Produtos Veterinários}

$\mathrm{O}$ mercado de produtos veterinários no Brasil era bastante pulverizado, sendo que a maior empresa possuía $10 \%$ de participação no mercado. Estimava-se em cerca de 200 o número de empresas no setor.

Em função de o Brasil possuir o maior rebanho comercial de bovinos do mundo, este se tornava um grande foco das empresas atuantes no mercado. O Brasil possuía um plantel de quase 200 milhões de cabeças de gado, o que se constituía em um mercado, sem dúvida, interessante. O mercado veterinário brasileiro havia respondido, em 2004, por mais de $\mathrm{R} \$ 2$ bilhões em faturamento ou cerca de US\$ 700 milhões. O mercado mundial foi estimado em quase US\$ 14 bilhões no mesmo ano.

Tabela 2 - Segmentação de mercado por classes terapêuticas

\begin{tabular}{cccc}
\hline & $\begin{array}{c}\text { Mercado Brasileiro de Produtos Veterinários: } \\
\text { Faturamento do Setor no Brasil }\end{array}$ & $\begin{array}{c}\text { Mercado Global de } \\
\text { Produtos Veterinários }\end{array}$ \\
\hline Ano & R $\$$ & US\$ & US\$ \\
\hline 2000 & 1.412 .968 .610 & 771.479 .436 & 11.030 .000 .000 \\
2001 & 1.502 .530 .732 & 636.620 .315 & 11.050 .000 .000 \\
2002 & 1.713 .696 .010 & 596.331 .256 & 11.330 .000 .000 \\
2003 & 1.869 .203 .030 & 614.117 .829 & 12.545 .000 .000 \\
2004 & 2.058 .202 .871 & 706.522 .679 & 13.710 .000 .000 \\
2005 & 2.210 .795 .586 & 917.453 .680 & 17.400 .000 .000 \\
2006 & 2.302 .303 .276 & 1.057 .885 .782 & 16.100 .000 .000 \\
\hline
\end{tabular}

Fonte: Research and Markets (2006), Sindan (2007) e Merial (2009). 


\section{Caso Ouro Fino Saúde Animal}

A participação dos produtos para bovinos representava $57 \%$ do total de produtos veterinários no mercado brasileiro. Dentro deste grupo, a maior parte estava concentrada na área de biológicos, mais especificamente, nas vacinas contra febre aftosa.

Tabela 3 - Segmentação de mercado por classes terapêuticas

\begin{tabular}{lccc}
\hline \multicolumn{3}{c}{ Participação Relativa das Espécies no Mercado de Saúde Animal - 2005 } \\
\hline \multicolumn{1}{c}{ Espécie } & Mundo & Brasil \\
\hline Bovinos & $27 \%$ & $57 \%$ \\
Ovinos & $5 \%$ & $3 \%$ \\
Suínos & $16 \%$ & $9 \%$ \\
Aves & $11 \%$ & $18 \%$ \\
Animais de companhia (pet) / outros & $40 \%$ & $13 \%$
\end{tabular}

Fonte: Wood Mackenzie (2005) apud Capanema et al. (2007) e Sindan (2005) apud Capanema et al. (2007).

\section{A Febre Aftosa}

A doença conhecida como febre aftosa era causada por um vírus que possuía sete tipos diferentes: O, A, C, Asia 1, SAT1, SAT2, e SAT3, com até 80 subtipos divididos entre esses grupos. Na América do Sul, foram encontrados vírus dos tipos A, O e C. A doença era uma enfermidade altamente contagiosa que atacava vários animais, principalmente bovinos, suínos, ovinos e caprinos, mas era a doença era inofensiva ao ser humano.

A contaminação de animais sadios podia ocorrer de diferentes formas: por meio da salivação excessiva dos animais doentes, que eliminavam os vírus na pastagem e no solo, contaminando novas cabeças do rebanho; pelo vento, que podia disseminar o vírus da aftosa em distâncias de até $60 \mathrm{~km}$, alastrando o problema para outras áreas; e, além disso, os vírus podiam continuar ativos mesmo depois da morte do animal, presentes na medula óssea, gânglios e vísceras. Caso essa carne fosse transportada para outras localidades, podia contaminar outros rebanhos. Por isso, a exportação de carnes ficava comprometida, afetando a economia da região atingida pela doença.

O gado infectado apresentava sintomas como febre, salivação excessiva e formação de vesículas na mucosa bucal e entre os cascos, o que causa problemas na alimentação e locomoção. Em consequência disso, havia quebra da produção leiteira, perda de peso, crescimento retardado e menor eficiência reprodutiva (inclusive abortos). Além disso, as propriedades que tinham animais doentes eram interditadas e a exportação da carne e dos produtos derivados tornava-se difícil. Não existia tratamento para a doença. As únicas medidas possíveis eram profiláticas. 


\section{As Campanhas de Vacinação}

O governo federal instituiu, em 1963, no âmbito do Ministério da Agricultura, a Campanha Nacional contra a Febre Aftosa. Em 1992, a política e as estratégias de combate à febre aftosa foram revisadas objetivando a erradicação desta doença do território nacional. Desde então, o Programa Nacional de Erradicação da Febre Aftosa (Pnefa) obteve grandes avanços, com incorporação de mais de 50\% das terras brasileiras e mais de $80 \%$ dos rebanhos bovino e suíno na zona livre de febre aftosa com vacinação.

O rebanho brasileiro era vacinado duas vezes ao ano para ativar o sistema imunológico dos animais e evitar a contaminação da doença. Eram vacinados todos os animais, machos e fêmeas (desde bezerros recém-nascidos a animais adultos). Os produtores rurais tinham liberdade para escolher a vacina mais adequada, tendo que comprovar sua compra ao Ministério. A imunidade contra um dos tipos de vírus de febre aftosa não protegia contra os outros. Assim, a vacina contra febre aftosa comercializada no Brasil era trivalente, ou seja, continha os três subtipos de vírus existentes no país - os subtipos O, A e C. Vacinas bivalentes eram produzidas em escala bastante reduzida apenas para fins de exportação.

A vacina garantia imunidade por 6 meses, devendo então ser reaplicada. A validade da vacina como produto era de 24 meses, desde que atendidas às condições de conservação (a principal: manutenção em temperatura entre 2 a $8^{\circ} \mathrm{C}$ ), o que permitia estoques. A dosagem por animal era sempre a mesma, independentemente do peso e da idade, de $5 \mathrm{ml}$ no Brasil. A fabricação da vacina era feita em processo de escalonamento (parte-se de pequenos volumes aumentando-os gradualmente). A principal matéria-prima era o vírus.

\section{O Mercado de Biológicos}

O mercado de biológicos representava $29 \%$ do mercado de produtos veterinários no Brasil. Destes, boa parte correspondia à comercialização de vacinas para febre aftosa. Pela obrigatoriedade de vacinação na maior parte do país, as empresas possuíam um mercado total praticamente garantido. Cabia às empresas competir por uma participação maior neste mercado.

$\mathrm{O}$ preço de uma dose de vacina para febre aftosa variava de empresa para empresa. $\mathrm{O}$ preço no início de 2005 se situava entre $\mathrm{R} \$ 1,15$ e $\mathrm{R} \$ 1,20$ a dose. O valor era constantemente reajustado ao longo dos anos. Havia informações de que ela havia custado, em média, cerca de R 0,32 em 1998, R\$ 0,66 em 1999 e R \$ 0,80 em 2002. 
Caso Ouro Fino Saúde Animal

Tabela 4 - Segmentação de mercado por classes terapêuticas

Panorama da produção de vacinas contra febre aftosa em 2004 no Brasil

Produção*

Exportação (Bolívia/Paraguai/Uruguai) Importação

Estoque (produzido antes de 2004)
Doses de vacina contra a febre aftosa

\begin{tabular}{ccc}
\multicolumn{3}{c}{ Doses de vacina contra a febre aftosa } \\
\hline Trivalente & Bivalente** $^{* *}$ & Total \\
\hline 311.058 .060 & 13.249 .960 & 324.308 .020 \\
16.200 .390 & 11.000 .000 & 27.200 .390 \\
0 & 0 & 0 \\
117.558 .320 & 0 & 117.558 .320
\end{tabular}

* Apenas as aprovadas em controle e disponibilizadas para o comércio / ** Bivalente: apenas vírus tipos A e O. Fonte: MAPA, 2005.

O resultado das campanhas de vacinação mostrava também um crescimento consistente, puxado pela ampliação do rebanho brasileiro e pelo maior percentual de animais vacinados. Somando-se a vacinação e a revacinação, já que os animais eram vacinados duas vezes ao ano, o consumo de doses de vacina tinha totalizado quase 333 milhões em 2004.

Tabela 5 - Segmentação de mercado por classes terapêuticas

\begin{tabular}{ccccc}
\hline \multicolumn{5}{c}{ Evolução do resultado das campanhas de vacinação contra febre aftosa no Brasil } \\
\hline Ano & $\begin{array}{c}\text { População } \\
\text { existente (bovina e } \\
\text { bubalina) }\end{array}$ & $\begin{array}{c}\text { Total de animais } \\
\text { vacinados }\end{array}$ & $\begin{array}{c}\text { Percentual de } \\
\text { cobertura vacinal }\end{array}$ & $\begin{array}{c}\text { Doses aplicadas (vacinação e } \\
\text { revacinação) }\end{array}$ \\
\hline 1994 & 159.227 .797 & 102.326 .522 & $64 \%$ & 198.816 .883 \\
1995 & 158.503 .190 & 107.543 .498 & $68 \%$ & 207.733 .516 \\
1996 & 155.368 .527 & 114.731 .921 & $74 \%$ & 218.312 .698 \\
1997 & 158.446 .481 & 123.911 .138 & $78 \%$ & 228.809 .106 \\
1998 & 158.009 .814 & 131.200 .698 & $83 \%$ & 236.562 .873 \\
1999 & 160.395 .129 & 139.950 .430 & $87 \%$ & 232.017 .381 \\
2000 & 166.974 .605 & 147.718 .162 & $88 \%$ & 277.505 .686 \\
2001 & 170.625 .996 & 156.101 .114 & $91 \%$ & 292.629 .840 \\
2002 & 183.668 .123 & 157.639 .726 & $86 \%$ & 313.502 .481 \\
2003 & 192.246 .837 & 180.948 .940 & $94 \%$ & 332.788 .563 \\
2004 & 198.941 .557 & 188.653 .738 & $95 \%$ & \\
\hline
\end{tabular}

Fonte: MAPA, 2005.

\section{A Concorrência}

A concorrência no mercado de vacinas para febre aftosa no Brasil resumia-se a seis empresas: Merial, Bayer, Intervet, Pfizer, Schering-Plough e Vallée. Dessas, apenas a Vallée era uma empresa de capital nacional. Todas as demais eram subsidiárias de multinacionais.

A Merial Saúde Animal fabricava a vacina Aftobov ${ }^{\circledR}$ Oleosa. Havia faturado R\$ 260 milhões em 2005, com crescimento de $22 \%$ sobre o ano anterior (R \$ 213 milhões). A empresa era a líder do mercado nacional de produtos para saúde animal. O complexo aftosa respondia por 30 35\% da receita. Em termos mundiais, a Merial obteve faturamento de US\$1,9 bilhão em 2005, representando cerca de $11 \%$ do mercado global. Resultado de joint-venture entre Merck \& Co. e Sanofi-Aventis, a empresa tinha 5.000 funcionários e estava presente em mais 
de 150 países. Sua capacidade de produção de vacinas para aftosa no Brasil era de cerca de 200 milhões de doses anuais em Paulínia/SP.

A Bayer fabricava a vacina Bayovac® Oleosa. Tinha uma capacidade de produção de vacinas para aftosa no Brasil estimada em 120 milhões de doses anuais localizada em Porto Alegre/RS. Essa divisão da Bayer faturou R\$ 140 milhões em 2005, $20 \%$ mais que no ano anterior. As vacinas da febre aftosa abrangiam $45 \%$ das vendas totais da área de Saúde Animal. Somente no ano passado foram comercializadas mais de 110 milhões de doses. As vacinas para febre aftosa eram o principal negócio dessa área. Tinham cerca de $10 \%$ do mercado de vacinas, e perspectivas de atender $15 \%$ no curto prazo.

A Intervet fabricava a vacina Aftovacin ${ }^{\circledR}$ Oleosa. Era uma empresa pertencente ao grupo Akzo Nobel. No Brasil, a matriz da Intervet ficava localizada em São Paulo/SP. Além disso, possuía duas fábricas: em Fortaleza /CE (produção de vacina contra febre aftosa e produtos estéreis injetáveis, tais como antibióticos e endectocidas) e em Cruzeiro/SP (produção de antiparasitários e antibióticos).

A Pfizer comercializava a vacina Pfizervac ${ }^{\circledR}$ Oleosa e era o maior conglomerado farmacêutico do mundo. Bastante focada no segmento de saúde humana, ela era reconhecida principalmente pelo seu principal produto, o Viagra. No entanto, a empresa não possuía fábricas para produção de vacina contra aftosa. A produção era terceirizada pela Merial.

A Schering-Plough comercializava a vacina Oleovac® $\mathrm{SH}$, com vendas estimadas em 75 milhões de doses anuais. Assim como a Pfizer, também era um grande grupo farmacêutico focado fortemente em produtos para a saúde humana. Faturou R \$ 179 milhões com saúde animal em 2004 no Brasil. Só com produtos veterinários, a Schering-Plough Animal Health faturava US\$ 700 milhões por ano no mundo. A produção era terceirizada pela Bayer.

A Vallée fabricava a vacina Bovicel e tinha capacidade de produção estimada em 25 milhões de doses anuais em sua fábrica em Montes Claros/MG. Foi criada em 1961 em Uberlândia/MG. Em 1998 instalou um laboratório biosseguro para fabricação da vacina. Trabalhava principalmente nos segmentos de biológicos (vacinas), antiparasitários, suplementos e terapêuticos.

Estimativas do Sindicato Nacional da Indústria de Produtos para Saúde Animal apontavam que a capacidade de produção instalada no Brasil era de cerca de 500 milhões de doses anuais, sendo um dos maiores polos produtores de vacinas para febre aftosa do mundo.

$\mathrm{Na}$ Argentina, a empresa Biogénesis-Bagó tinha capacidade de produção estimada em 180 milhões de doses anuais de vacinas para febre aftosa. Tratava-se da maior empresa naquele mercado, praticamente monopolista. Embora dispusesse de filial em Curitiba-PR, ela 
não exportava a vacina para o Brasil. Configurava-se, portanto, em concorrência potencial. $\mathrm{Na}$ Colômbia também havia duas empresas que fabricavam a vacina, uma privada e uma de capital misto, porém com posições menos expressivas.

\section{A Entrada no Novo Mercado}

Diante da necessidade de dar um passo maior em direção ao crescimento sustentável, a empresa não poderia deixar de entrar no mercado de biológicos. No entanto, era um passo arriscado. Se escolhesse por produzir a vacina, estimava-se que seriam praticamente 3 anos até sua produção. Cada dose de vacina produzida tinha um custo projetado de $\mathrm{R} \$ 0,60$. Além disso, quem lhes passaria o know-how de produção?

Um outro ponto incomodava principalmente o diretor financeiro. O custo de implantação de uma unidade de biológicos poderia chegar a quase R\$ 30 milhões, considerando-se uma capacidade de 60 milhões de doses por ano. A manipulação de vacinas deste tipo exigia um nível de biossegurança III na fábrica, que implicava na duplicação de praticamente todas as utilidades, além de um controle rígido do ambiente fabril (controle de umidade, de temperatura e, em alguns casos, até de pressão). Era um investimento muito alto.

No entanto, o investimento interno abriria mais horizontes. A empresa poderia fabricar outros tipos de vacina, com mais autonomia. Talvez algum laboratório público pudesse lhes ajudar neste momento, afinal a empresa tinha trabalhado algumas parcerias ao longo dos anos. Estimativas da empresa apontavam que ela poderia atingir vendas de 40 milhões de doses no curto prazo.

Por outro lado, o Brasil dispunha de capacidade ociosa na fabricação de vacinas. Neste caso, a empresa poderia se associar a uma outra empresa, como outras já faziam. Assim, com muita rapidez, poderia prover as vacinas para seus 8.000 clientes. As alternativas poderiam envolver o desenvolvimento de kits, explorando não só a venda da vacina, como de outros produtos para bovinos. Além disso, seria possível exportar mais rapidamente.

Alguns contatos com empresas fabricantes já haviam sido feitos, no Brasil e no exterior. Será que alguém se disporia a fornecer para a empresa? A que preço?

Da mesma forma, a empresa buscava também alternativas para uma eventual produção no Brasil. Restava decidir. Que estratégia seria mais adequada para a empresa? Montar toda uma estrutura nova para a produção de biológicos ou se associar a uma empresa produtora? 
Bernardo Hauch Ribeiro de Castro

\section{ANEXOS}

Anexo 1: 10 Maiores Empresas de Produtos Veterinários no Brasil (jul/2004 a jun/2005)

\begin{tabular}{ccc||ccc}
\hline Colocação & Empresa & Participação & Colocação & Empresa & Participação \\
\hline $1^{\mathbf{0}}$ & Merial & $10,3 \%$ & $6^{\mathbf{0}}$ & Fort Dodge & $5,7 \%$ \\
$2^{\mathbf{o}}$ & Pfizer & $9,9 \%$ & $7^{\mathbf{0}}$ & Elanco & $4,7 \%$ \\
$3^{\text {o }}$ & Schering-Plough & $8,7 \%$ & $8^{\mathbf{0}}$ & Bayer & $4,2 \%$ \\
$4^{\text {o }}$ & Intervet & $7,2 \%$ & $9^{\circ}$ & Ouro Fino & $3,8 \%$ \\
$5^{\text {o }}$ & Vallée & $6,6 \%$ & $10^{\mathbf{o}}$ & Novartis & $3,3 \%$ \\
\hline
\end{tabular}

Anexo 2

* Fonte: Sindan (2005) apud Capanema et al. (2007).

\begin{tabular}{lc|lc}
\hline \multicolumn{2}{c|}{$\begin{array}{c}\text { Mercado Veterinário Brasileiro por Classe } \\
\text { Terapêutica - 2005 }\end{array}$} & \multicolumn{2}{c}{$\begin{array}{c}\text { Participação Relativa dos Produtos no } \\
\text { Mercado Mundial de Saúde Animal - 2004 }\end{array}$} \\
\hline \multicolumn{1}{c|}{ Grupo de Produtos } & $\%$ & \multicolumn{1}{c}{ Grupo de Produtos } & $\%$ \\
\hline Biológicos (vacinas) & $29,4 \%$ & Parasiticidas & $29 \%$ \\
Antimicrobianos & $21,3 \%$ & Biológicos (vacinas) & $23 \%$ \\
Ectoparasiticidas & $13,1 \%$ & Tratamento de infecções & $16 \%$ \\
Endectocidas & $13,0 \%$ & Aditivos alimentares & $13 \%$ \\
Endoparasiticidas/Vermífugos & $9,0 \%$ & Outros farmacêuticos & $20 \%$ \\
Terapêuticos & $4,1 \%$ & & \\
Tônicos/Fortificantes & $3,5 \%$ & & \\
Desinfetantes & $2,4 \%$ & & \\
Dermatológicos & $0,8 \%$ & & \\
Outras categorias & $3,5 \%$ & \\
Fonte: Sindan (2005) apud Capanema et al. (2007); Wood Mackenzie (2005) apud Capanema et al. (2007)
\end{tabular}

\section{Anexo 3: Notas de Ensino (não disponibilizar aos alunos)}

Objetivo do Caso: Este é um caso para o ensino de estratégia em cursos de pós-graduação em administração. O Caso leva o aluno a, na posição dos executivos da empresa, tomar uma decisão de como entrar em um novo mercado, o que requer um conjunto de novos conhecimentos que a empresa não possui. Embora este guarde sinergias com os mercados já explorados pela empresa, não se trata de uma entrada trivial. A principal questão é decidir se a empresa deve entrar no mercado comprando produtos de terceiros ou fabricando seus próprios. O investimento na segunda alternativa é elevado, dada a especificidade do negócio. Os alunos, portanto, são levados a refletir sobre as vantagens e desvantagens de cada uma das alternativas e a tomar uma decisão. Obs.: o caso tenta utilizar, na medida do possível, dados reais. Uma exceção é o custo de produção de uma dose de vacina. Como este dado é estratégico e variável conforme a escala de produção, optamos por definir um valor arbitrário $(\mathrm{R} \$ 0,60)$ para permitir as análises financeiras.

Questão que os alunos devem responder em sua preparação: Que estratégia seria mais adequada para a empresa entrar no mercado de vacinas? (A questão encontra-se de forma explícita no caso e está citada de forma resumida apenas a título de referência). 


\section{Pré-requisitos dos alunos e Materiais de referência}

O caso não exige nenhum pré-requisito específico dos alunos para sua discussão, embora noções de estratégia e/ou finanças sejam desejáveis para uma análise mais profunda. Os conceitos centrais podem ser apresentados na própria aula. O caso também não utiliza qualquer material de referência adicional. Leituras adicionais podem conter textos básicos de estratégia, opcionais, a critério do professor.

\section{Sugestões de questões a serem formuladas para os alunos}

Algumas questões podem ser colocadas pelo professor para estimular ou auxiliar o processo de discussão do caso em sala de aula. A seguir estão listadas algumas sugestões.

\begin{tabular}{|c|l|}
\hline 1 & Que proposta os executivos devem levar aos sócios? (questão principal do caso) \\
\hline 2 & Quais as vantagens e desvantagens das duas opções? \\
\hline 3 & O investimento em uma nova estrutura de produção compensa financeiramente? \\
\hline 4 & $\begin{array}{l}\text { Haveria alguma empresa interessada na venda de vacinas para a empresa? (afinal, são apenas quatro } \\
\text { empresas fabricantes) }\end{array}$ \\
\hline 5 & Fabricar internamente não dá mais autonomia para a empresa? \\
\hline 6 & A que preço as concorrentes estariam dispostas a fornecer para a empresa? \\
\hline 7 & $\begin{array}{l}\text { Há empresas estrangeiras com potencial de entrada no Brasil. Neste caso, não seria o tempo uma questão } \\
\text { central para a decisão? (Esta pergunta utiliza os dados do tópico "A Concorrência", que identifica a } \\
\text { empresa Biogénesis-Bagó como potencial entrante.) }\end{array}$ \\
\hline 8 & $\begin{array}{l}\text { Há espaço para a empresa entrar neste novo mercado? Ele é bem atendido hoje pelas empresas já } \\
\text { atuantes? (Esta pergunta questiona as bases do caso. Faz sentido entrar neste novo mercado? Pode-se } \\
\text { fazer uma análise particular neste caso, combinando os dados de crescimento do mercado pelas } \\
\text { campanhas de vacinação (tópico "O Mercado de Biológicos") e o posicionamento da concorrência). }\end{array}$ \\
\hline 9 & $\begin{array}{l}\text { Que conhecimentos a empresa deve desenvolver para ter sucesso no novo negócio? (A intenção desta } \\
\text { pergunta é mostrar que as competências são diferentes conforme a alternativa escolhida. Para compra da } \\
\text { vacina, a competência a desenvolver é a habilidade de negociação e a gestão administrativa e de contratos. } \\
\text { Para fabricar a vacina, a competência a desenvolver é técnica (como fabricar). Em ambas, é preciso } \\
\text { desenvolver a competência comercial e de assistência técnica, já que o produto é novo para a empresa.) }\end{array}$ \\
\hline 10 & $\begin{array}{l}\text { Na sua opinião, entrar neste novo negócio é uma decisão acertada para uma estratégia de crescimento? } \\
\text { (Assim como a pergunta 8, busca refletir sobre a decisão já tomada, de entrar no mercado de biológicos.) }\end{array}$ \\
\hline 11 & $\begin{array}{l}\text { É interessante a empresa considerar a aquisição da operação de vacina para febre aftosa de uma de suas } \\
\text { concorrentes? }\end{array}$ \\
\hline
\end{tabular}

\section{Análise}

\section{Alternativa A: Comprar a vacina de terceiros}

\begin{tabular}{|l|l|}
\hline Vantagens & Explicação \\
\hline $\begin{array}{l}\text { Custo menor de } \\
\text { implantação } \\
\text { inicial }\end{array}$ & $\begin{array}{l}\text { O custo de implantação de uma fábrica de vacinas de porte condizente com a entrada } \\
\text { planejada pela empresa estava estimado em R\$ 30 milhões, para uma empresa que fatura } \\
\text { pouco mais de R\$ 100 milhões por ano. O custo de produção por terceiros não requer } \\
\text { desembolsos iniciais. Obs: vide o tópico “A Entrada no Novo Mercado" para o custo de } \\
\text { construção da fábrica. }\end{array}$ \\
\hline $\begin{array}{l}\text { Rapidez na } \\
\text { implantação }\end{array}$ & $\begin{array}{l}\text { A construção de uma fábrica de vacinas poderia levar cerca de 3 anos até sua entrada em } \\
\text { operação. A alternativa de compra de terceiros não teria este prazo de carência. Obs: vide } \\
\text { o tópico "A Entrada no Novo Mercado" para as informações sobre prazo. }\end{array}$ \\
\hline $\begin{array}{l}\text { Não são } \\
\text { necessários } \\
\text { conhecimentos } \\
\text { específicos sobre a }\end{array}$ & $\begin{array}{l}\text { A operação de uma fábrica de vacinas difere da operação de plantas industrias em outros } \\
\text { grupos de produtos. É fácil deduzir que a fabricação de vacinas com vírus inativos é } \\
\text { diferente da produção de aerossóis e outros produtos tópicos. Requer conhecimento novo, } \\
\text { tanto de fabricação, quanto de armazenagem e distribuição. Além disso, conforme }\end{array}$ \\
\hline
\end{tabular}




\begin{tabular}{|l|l|}
\hline $\begin{array}{l}\text { produção de } \\
\text { vacinas }\end{array}$ & $\begin{array}{l}\text { informações do tópico “A Entrada no Novo Mercado", a fábrica teria um nível de } \\
\text { biossegurança III, que, por si só, já implicaria em diversas novas rotinas (controle de } \\
\text { acesso, de dejetos, de entrada de matéria-prima etc.). }\end{array}$ \\
\hline $\begin{array}{l}\text { Rápida entrada no } \\
\text { mercado }\end{array}$ & $\begin{array}{l}\text { Por ser um mercado bastante regulado, uma nova vacina precisa atender a alguns critérios } \\
\text { e passar por testes, o que não é o caso aqui enumerar. Comprando uma vacina já } \\
\text { comercializada no mercado e com registro nos respectivos órgãos reguladores, torna-se } \\
\text { mais rápida a entrada no mercado. }\end{array}$ \\
\hline $\begin{array}{l}\text { Há capacidade } \\
\text { ociosa de } \\
\text { produção no } \\
\text { Brasil }\end{array}$ & $\begin{array}{l}\text { Conforme estimativas do SINDAN - Sindicato Nacional da Indústria de Produtos para } \\
\text { Saúde Animal, a capacidade instalada no Brasil é de cerca de 500 milhões de doses anuais } \\
\text { (tópico "A Concorrência"), enquanto as doses aplicadas no Brasil em 2004 foram de } \\
\text { pouco menos de 333 milhões (tópico "O Mercado de Biológicos"). }\end{array}$ \\
\hline $\begin{array}{l}\text { Há experiências } \\
\text { anteriores de } \\
\text { terceirização neste } \\
\text { setor }\end{array}$ & $\begin{array}{l}\text { Há dois casos de terceirização da produção: a Pfizer, que utilizava vacinas fabricadas pela } \\
\text { Merial, e a Schering-Plough, que utilizava vacinas da Bayer (vide o tópico "A } \\
\text { Concorrência"). }\end{array}$ \\
\hline
\end{tabular}

\begin{tabular}{|c|c|}
\hline Desvantagens & Explicação \\
\hline $\begin{array}{l}\text { A empresa não incorpora } \\
\text { conhecimentos que } \\
\text { podem ser importantes } \\
\text { no futuro }\end{array}$ & $\begin{array}{l}\text { O setor de Biológicos engloba outras vacinas, onde a vacina para febre aftosa, no } \\
\text { caso brasileiro, é a mais significativa. Uma planta própria de biológicos poderia } \\
\text { trazer a possibilidade de fabricar ou desenvolver outras vacinas. Esta hipótese é } \\
\text { rapidamente mencionada no tópico "A Entrada no Novo Mercado". }\end{array}$ \\
\hline $\begin{array}{l}\text { Há aparentemente } \\
\text { poucos fornecedores, o } \\
\text { que pode representar um } \\
\text { risco para a empresa }\end{array}$ & $\begin{array}{l}\text { O mercado de vacinas para febre aftosa é relativamente concentrado. São apenas } 4 \\
\text { empresas com capacidade instalada no país (vide tópico "A Concorrência") e a } \\
\text { possibilidade de importação, embora não identificada no caso, sofre das mesmas } \\
\text { características de concentração, além de sofrer com um custo adicional de } \\
\text { transporte (produto perecível, com necessidade de refrigeração; vide tópico "As } \\
\text { Campanhas de Vacinação"). }\end{array}$ \\
\hline $\begin{array}{l}\text { Sendo seus concorrentes } \\
\text { grandes multinacionais, } \\
\text { dificilmente a empresa } \\
\text { encontraria algum outro } \\
\text { fornecedor no exterior }\end{array}$ & $\begin{array}{l}\text { O caso identifica uma empresa com potencial para fornecer a vacina contra febre } \\
\text { aftosa, a partir da Argentina (tópico "A Concorrência"). No entanto, este seria } \\
\text { provavelmente o único caso. }\end{array}$ \\
\hline $\begin{array}{l}\text { A margem de venda seria } \\
\text { reduzida }\end{array}$ & $\begin{array}{l}\text { Dificilmente o eventual parceiro aceitaria vender a preços mais baixos que a venda } \\
\text { direta no mercado. Estimando em } \mathrm{R} \$ 1,15 \text { a dose, a empresa poderia vendê-la } \\
\text { talvez a R } \$ 1,20 \text {, observando-se apenas a variação de preço no mercado (vide o } \\
\text { tópico "O Mercado de Biológicos" para os preços). Isto, para vendas na faixa de } 40 \\
\text { milhões de doses (vide o tópico "A Entrada no Novo Mercado" para a estimativa de } \\
\text { doses desejada pela empresa), traria uma renda anual de } \mathrm{R} \$ 2 \text { milhões (resultado de } \\
40 \text { milhões multiplicado pela diferença entre o preço de venda, R } \$ 1,20 \text {, e o preço } \\
\text { de compra, } \mathrm{R} \$ 1,15 \text { ), sendo considerado, provavelmente, um negócio menor, visto } \\
\text { que a divisão do mercado estima um potencial de faturamento muito maior (vide } \\
\text { Anexo } 2 \text { para a divisão do mercado por grupo de produtos). Por outro lado, vender } \\
\text { a um preço maior que } \mathrm{R} \$ 1,20 \text { colocaria a competitividade em xeque. }\end{array}$ \\
\hline
\end{tabular}

Para avaliar esta alternativa é preciso identificar as possibilidades de produção e venda de vacinas para a empresa. Sugere-se avaliar a capacidade produtiva ociosa, as possibilidades de mercado para esta "produção extra", assim como discutir se, do ponto de vista do fornecedor, seria um bom negócio. Seria interessante discutir se, no longo prazo, a estratégia de comprar de terceiros é sustentável. 


\begin{tabular}{|c|c|}
\hline Vantagens & Explicação \\
\hline $\begin{array}{l}\text { A empresa pode } \\
\text { incorporar } \\
\text { conhecimentos vitais } \\
\text { para seu futuro }\end{array}$ & $\begin{array}{l}\text { O setor de Biológicos engloba outras vacinas, onde a vacina para febre aftosa, no caso } \\
\text { brasileiro, é a mais significativa. Uma planta própria de biológicos poderia trazer a } \\
\text { possibilidade de fabricar ou desenvolver outras vacinas. Esta hipótese é rapidamente } \\
\text { mencionada no tópico "A Entrada no Novo Mercado"). }\end{array}$ \\
\hline $\begin{array}{l}\text { Dominando o processo } \\
\text { produtivo, ela teria } \\
\text { mais flexibilidade e } \\
\text { autonomia em relação } \\
\text { aos fornecedores }\end{array}$ & $\begin{array}{l}\text { Ter sua própria planta traz para dentro da empresa a decisão de fabricação. Não há } \\
\text { necessidade de negociar lotes adicionais ou contratos de fornecimento, como seria } \\
\text { necessário em casos de terceirização. Embora o caso não traga dados específicos sobre } \\
\text { isto, bibliografia complementar sobre terceirização, a critério do professor, pode trazer } \\
\text { informações sobre estas atividades. }\end{array}$ \\
\hline $\begin{array}{l}\text { No médio prazo, } \\
\text { compensa } \\
\text { financeiramente }\end{array}$ & $\begin{array}{l}\text { Estimando-se um custo de implantação em R } \$ 30 \text { milhões no } 1^{\circ} \text { ano e considerando-se } \\
\text { o início da produção para o } 4^{\circ} \text { ano, com vendas de } 40 \text { milhões de doses (vide o tópico } \\
\text { "A Entrada no Novo Mercado" para o custo de construção da fábrica e para a projeção } \\
\text { de vendas), o payback viria já no } 5^{\circ} \text { ano, com uma taxa interna de retorno de } 38 \% \text {. } \\
\text { Observação: cálculos realizados com preço de venda de R\$ } 1,15 \text { a dose (dado } \\
\text { disponível no tópico "O Mercado de Biológicos") e custo de produção de R\$ } 0,60 \text { a } \\
\text { dose (dado disponível no tópico "A Entrada no Novo Mercado"). }\end{array}$ \\
\hline $\begin{array}{l}\text { Maior facilidade em } \\
\text { buscar } \\
\text { complementaridade } \\
\text { entre produtos }\end{array}$ & $\begin{array}{l}\text { Uma das principais vantagens competitivas da empresa é seu portfólio de clientes, que } \\
\text { soma } 8.000 \text { (dado disponível no tópico "A Entrada no Novo Mercado"). Ter uma } \\
\text { produção própria possibilitaria adequar os produtos para atender de forma mais } \\
\text { adequada seus clientes, complementando produtos. }\end{array}$ \\
\hline
\end{tabular}

\begin{tabular}{|l|l|}
\hline Desvantagens & Explicação \\
\hline $\begin{array}{l}\text { Custo maior, } \\
\text { principalmente } \\
\text { para a implantação } \\
\text { da fábrica, }\end{array}$ & $\begin{array}{l}\text { O custo de implantação da fábrica era estimado em R\$ 30 milhões (vide o tópico "A } \\
\text { Entrada no Novo Mercado" para o custo de construção da fábrica). Para uma empresa do } \\
\text { tornando-se } \\
\text { um investimento de US\$ 15 milhões na nova fábrica, ainda em amortização (dado } \\
\text { captação externa } \\
\text { de recursos para } \\
\text { este investimento } \\
\text { acima das possibilidades da empresa. Embora os dados não estejam totalmente disponíveis } \\
\text { no caso, é possível afirmar que a geração de caixa não seria suficiente para atender a este } \\
\text { investimento. Isto levava a uma outra desvantagem, a necessidade de captação externa com } \\
\text { uma faixa de endividamento já elevada, o que prejudicava as condições de um eventual } \\
\text { financiamento. }\end{array}$ \\
\hline $\begin{array}{l}\text { Implantação mais } \\
\text { lenta }\end{array}$ & $\begin{array}{l}\text { A construção de uma fábrica de vacinas poderia levar cerca de 3 anos até sua entrada em } \\
\text { operação (vide o tópico “A Entrada no Novo Mercado). }\end{array}$ \\
\hline $\begin{array}{l}\text { Requer } \\
\text { conhecimentos } \\
\text { técnicos que a } \\
\text { empresa não } \\
\text { domina }\end{array}$ & $\begin{array}{l}\text { A operação de uma fábrica de vacinas difere da operação de plantas industrias em outros } \\
\text { grupos de produtos. É fácil deduzir que a fabricação de vacinas com vírus inativos é } \\
\text { diferente da produção de aerossóis e outros produtos tópicos. Requer conhecimento novo, } \\
\text { tanto de fabricação, quanto de armazenagem e distribuição. Além disso, conforme } \\
\text { informações no tópico “A Entrada no Novo Mercado", a fábrica teria um nível de } \\
\text { biossegurança III, que, por si só, já implicaria em diversas novas rotinas (controle de } \\
\text { acesso, de dejetos, de entrada de matéria-prima etc.). }\end{array}$ \\
\hline
\end{tabular}

Sugere-se, para avaliar esta alternativa, calcular as possibilidades de ganho da empresa com o novo negócio. O caso fornece dados sobre o custo e o tempo de implantação da nova fábrica - que, para fins de simplificação, pode ser admitido como constante para diversos volumes -, sobre o preço unitário das doses de vacina e sobre a perspectiva do mercado de vacinas para os próximos anos. Com base nestes dados, é possível calcular qual a expectativa de faturamento para o novo negócio em função do volume de produção. É possível estimar também o volume de vendas ao longo dos anos levando-se em consideração a existência de 
outros players no mercado. Questionamentos sobre a certeza sobre os prazos e os custos de implantação de uma fábrica de biológicos também podem ser alvo de discussão.

Alternativa $C$ : Aquisição de uma das empresas concorrentes, que possua know-how e estrutura para a produção de vacinas

\begin{tabular}{|l|l|}
\hline Vantagens & Explicação \\
\hline Rapidez na implantação & $\begin{array}{l}\text { Embora a discussão em direção a esta aquisição possa levar } \\
\text { tempo, após concretização, a nova empresa já traria o know-how } \\
\text { e a estrutura para fabricação e comercialização da vacina para } \\
\text { febre aftosa. }\end{array}$ \\
\hline $\begin{array}{l}\text { Possibilidade de ganhar conhecimentos } \\
\text { com rapidez pela incorporação de pessoal }\end{array}$ & $\begin{array}{l}\text { A aquisição poderia alavancar este segmento na empresa, com a } \\
\text { incorporação de conhecimento novo. }\end{array}$ \\
\hline
\end{tabular}

\begin{tabular}{|l|l|}
\hline Desvantagens & Explicação \\
\hline Não há muitos & $\begin{array}{l}\text { Como se observa no tópico "A Concorrência", havia apenas 4 empresas com unidades de } \\
\text { casos a } \\
\text { considerar para } \\
\text { uma eventual } \\
\text { subsidiárias de grandes conglomerados multinacionais, o que poderia complicar ainda mais } \\
\text { aquisição }\end{array}$ \\
$\begin{array}{l}\text { uma eventual negociação. Além disso, como este segmento especificamente era considerado } \\
\text { muito importante, dificilmente alguma empresa se disporia a vender o negócio isoladamente. }\end{array}$ \\
$\begin{array}{l}\text { possivelmente } \\
\text { elevado }\end{array}$ & $\begin{array}{l}\text { A aquisição de uma empresa com tal estrutura teria custo, provavelmente, pelo menos } \\
\text { equivalente à construção de uma unidade própria. Sendo assim, esta alternativa incorreria nos } \\
\text { mesmos pontos levantados para a alternativa de produzir a vacina. }\end{array}$ \\
\hline
\end{tabular}

Esta alternativa pode não ser levantada durante a discussão do caso. Tendo em vista que não é uma alternativa imediata, já que não está explícita ao longo do documento, a adicionamos aqui apenas como forma de cobrir as possibilidades. Se desejado, a alternativa pode ser levantada pelo próprio professor (pergunta $\mathrm{n}^{\circ} 8$ das "Sugestões de questões a serem formuladas para os alunos").

A viabilidade de aquisição de uma das empresas concorrentes vai depender da disponibilidade de recursos da empresa compradora e do preço imposto pelos vendedores. Como o mercado de indústrias que fabricam vacinas para febre aftosa no Brasil é pequeno apenas 4 indústrias - há indícios de que não haveria potenciais vendedores. Por outro lado, como em alguns casos o mercado de saúde animal é periférico para a multinacional, que tem na saúde humana seu principal foco, há a possibilidade de haver interessados. $\mathrm{O}$ caso não oferece muitos dados para uma análise mais precisa desta alternativa, ficando a discussão aberta para os alunos.

Observação: as alternativas listadas nestas notas de ensino podem não cobrir todas as possibilidades de análise. Sugerimos que haja uma reflexão prévia do professor sobre o caso a fim de identificar outras possibilidades em função das características de sua turma de alunos e do curso ministrado. 
Caso Ouro Fino Saúde Animal

\section{Outras Sugestões}

O caso permite a discussão de uma questão presente em outras indústrias dominadas por empresas estrangeiras. Tendo em vista o ambiente brasileiro, com condições frequentemente menos favoráveis que as de países desenvolvidos, é possível discutir sobre este ambiente ou sobre como uma empresa brasileira pode crescer neste mercado. Tendo este foco em vista, o caso pode ser também utilizado em cursos de políticas públicas, na medida que se poderia desenhar um papel de Estado no fortalecimento das empresas nacionais no setor.

\section{Plano de classe sugerido}

Recomenda-se que o caso seja fornecido antecipadamente aos alunos. O momento indicado para a utilização deste caso em um curso de pós-graduação em administração é em seu ponto intermediário/final, já que o conhecimento prévio de algumas ferramentas e de alguns conceitos de administração ajuda os alunos na construção das análises.

Sugere-se a estrutura a seguir (3 horas de duração):

\begin{tabular}{|l|c|}
\hline Apresentação e/ou discussão de temas correlatos & $1 \mathrm{~h} 15$ \\
\hline Intervalo & $15 \mathrm{~min}$ \\
\hline Discussão do caso em grupos de no máximo 5 alunos & $30 \mathrm{~min}$ \\
\hline Discussão do caso em plenária & $55 \mathrm{~min}$ \\
\hline Fechamento do caso (opcional) & $5 \mathrm{~min}$ \\
\hline
\end{tabular}

\section{REFERÊNCIAS BIBLIOGRÁFICAS PARA A PREPARAÇÃO DO CASO E DAS NOTAS DE ENSINO}

AUSTIN, J.E. Teaching Notes: Communicating the Teacher's Wisdom. Boston: HBS Publishing. Document 5-793-105. 9 de set. 1993.

CAPANEMA, L., VELASCO, L.O.M., SOUZA, J.O.B., NOGUTI, M.B. Panorama da indústria farmacêutica veterinária. In: BNDES Setorial, n.25, p.157-174, mar. 2007

DORAZI, A. O empresário [...], um dos sócios da [...], revela o caminho que o levou a construir a mais moderna indústria de produtos veterinários do Brasil. Revista Produz Brasília, Cases de Sucesso, p. 28-31, ago. 2005.

GESULLI, O.P. [...] é indicada ao Prêmio Empreendedor do ano 2003. Revista Avicultura Industrial, nov. 2003. Disponível em: http://www.aviculturaindustrial.com.br/site/dinamica.asp?tipo_tabela=negocios\&id=6629\&ca tegoria=empresas. Acesso em 15/8/2007. 
LEENDERS, M.R.; ERSKINE, J. Case Research: The Case Writing Process. 3.ed. The University of Western Ontario, 1989.

MAPA - Ministério da Agricultura, Pecuária e Abastecimento. Programa nacional de erradicação da febre aftosa: relatório anual 2004. Brasília: MAPA, 2005.

MARTINELLI, P. Vacinação sistemática - solução para aftosa. Portal Aprende Brasil, 2005. Disponível em: http://www.aprendebrasil.com.br. Acesso em 15/8/2007.

MERIAL. Strengthening our presence in animal Health, 30 Jun. 2009. Disponível em: http://en.sanofi-aventis.com/binaries/090730_merial_v3_tcm28-25796.pdf. Acesso em: $15 / 1 / 2010$.

RESEARCH AND MARKETS. World animal health markets. Informa Healthcare, Jan. 2006. Disponível em: http://www.researchandmarkets.com/reports/c78795. Acesso em: 15/1/2010.

ROBERTS, M.J. Developing a teaching case. Boston: HBS Publishing. Document 9-900-001, 1999. Rev. 9.Jun.2000.

SANCHEZ, V. Uma empresa que vale ouro: companhia de produtos veterinários, com capital $100 \%$ nacional, utiliza estratégias diferentes e se destaca num mercado de concorrência acirrada. Revista Marketing São Paulo, p.38-41, mar.2005.

SINDAN - Sindicato Nacional da Indústria de Produtos para Saúde Animal. Mercado veterinário. Disponível em: http://www.sindan.org.br. Acesso em 15/8/2007.

\section{SUGESTÕES DE BIBLIOGRAFIA COMPLEMENTAR}

FINE, C.H., WHITNEY, D.E. Is the Make-Buy Decision Process a Core Competence? Working Paper, n.3875-96. Cambridge: MIT, 1996. Disponível em: http://web.mit.edu/ctpid/www/Whitney/morepapers/make_buy.pdf. Acesso em 15/8/2007.

PROBERT, D.R. Developing a make or buy strategy for manufacturing business. London: Institution of Electrical Engineers, 1997.

VENKATESAN, R. Strategic sourcing: to make or not to make. Harvard Business Review, Nov/Dec.1992, p.98-107. 